\title{
RETIRA A QUEM ESCREVE SUA CANETA: GUIMARÃES ROSA E A SUBTRAÇÃO DA ESCRITA
}

Paulo de Andrade*

RESUMO:

\begin{abstract}
"Existirá algo em comum entre a experiência literária de Guimarães Rosa e as operações de subtração?" Essa pergunta, formulada a partir da leitura de Tutaméia, envia-nos ao movimento que aqui procuramos identificar como sendo próprio da escrita rosiana - condensar, abstrair, prescindir - e insinua a dimensão do elemento sobre o qual recai o trabalho do escritor: agora não mais tanto as palavras, mas, diminutamente, a letra.
\end{abstract}

PALAVRAS-CHAVE: Guimarães Rosa, subtração, letra.

Até hoje não sabia que se pode não escrever. Gradualmente, gradualmente, até que de repente a descoberta muito tímida: quem sabe, também eu poderia não escrever. Como é infinitamente mais ambicioso. É quase inalcançável.

Clarice Lispector

\section{VOLTAR, PARA FIM DE IDA}

Existem escritores que, livro após livro, não se cansam de perseguir a sua língua: aquela que está sempre por se fazer, ainda desconhecida e estrangeira para ele mesmo. Há também aqueles que se dão por satisfeitos - ou logrados - e, a certa altura, abandonam sua busca. Mas, quer se calem, quer perseverem, um trajeto enfim se desenha e, ao contrário do que pensa o senso comum, quase nunca é * Mestre em Letras: Estudos Literários (Área de concentração: Literatura Brasileira), 2001. 


\section{EMTESE}

Belo Horizonte, v. 6, p. I-253, ago. 2003

evolutivo, ascendente - uma vez que recomeçará a cada novo livro, infinitamente, chegando aqui mais longe, lá mais perto de um ponto que não sabemos se é o seu fim ou a sua perdição.

Assim, não seria de se espantar se encontrássemos um escritor que fizesse de seu percurso um eterno retorno, avançando sempre mais a cada vez que recuasse, que retornasse sem cessar ao começo que desde o início era já regresso. De que Guimarães Rosa seja esse escritor, assombrado pelo demônio de uma origem inoriginada, não temos dúvida: "Tudo, para mim, é viagem de volta". (Rosa, 1967: 13.) Mas que Tutaméia seja, desse tormento, a marca mais ambígua e fechada, a mais ilegivel e precisa - disso não podemos fugir. A despeito do grande silêncio que provoca em meio à crítica literária - que o vem tomando como diluição e esgotamento da obra -, Tutaméia rende-se sem medida à sua metamorfose, ao seu erro, seu nada.

Talvez não seja um livro o que temos diante de nós, mas talvez se trate de muito mais que um livro: a aproximação pura do movimento de onde vêm todos os livros, desse ponto original onde a obra decerto se perde, que sempre arruina a obra, que restaura nela a inacção sem fim, mas com o qual the é necessário manter uma relação cada vez mais inicial, sob pena de não ser nada. (Blanchot, 1984: 224.)

Por onde a obra começa? E como acaba? Por um livro, em livro, certamente. Mas quando começa, quando termina um livro? Se escrevemos um dicionário, uma enciclopédia, podemos sempre acrescentar novos verbetes, desfazer-nos de outros; temos ainda a liberdade de nos lançar à leitura a partir de qualquer palavra, saltar, retroceder, independente de ser esta a primeira página, aquela a última letra. Livro sem fim? Livro do princípio, que não acaba de acabar. E por que não enxergar aí - na própria forma do dicionário - o fim da literatura (sua meta, seu desfecho)? Tanto mais infinita quanto mais primordial, entregue ao risco de encontrar, no vazio de sua origem, sua ruína e seu desaparecimento.

Se tomamos Tutaméia como "a chave da obra" de Guimarães Rosa, como quer Assis Brasil (1969), por ver em suas páginas a imagem do pensamento que configuraria a poética do escritor e, portanto, seu "segredo", o dicionário de sua criação, aquilo que abre a obra, trazendo-a à luz, conferindo-lhe legibilidade, rapidamente não temos senão aquilo que a fecha, torna-a opaca e incompreensivel, rouba-1he 0 prestígio do dia e devolve-a à noite da dúvida. 
Composto por quarenta pequenas estórias que se seguem em ordem al fabética (à exceção de duas), um índice de leitura e outro de releitura, quatro prefácios, entre outros minuciosos detalhes de arquitetura, Tutaméia, último livro de Rosa publicado em vida, constrói-se pela decantação extrema de uma linguagem em que as palavras estão todas "medidas e pesadas, postas no seu exato lugar, não se podendo suprimir ou alterar mais de duas ou três em todo o livro sem desequilibrar o conjunto". (Rónai, 1985: 216) Essa exatidão, essa radicalidade imprime ao livro justamente uma parcela de indeterminação que repele a leitura tanto quanto a atrai - "'É para não entrarem! A casa é vossa...'" (Rosa, 1967: 37): casa de escrita traçada e soerguida a partir da substância física das palavras, alicerce tão sólido quanto volátil. E mais nos aproximamos, leitores, do arcabouço das palavras, mais elas voam, desfazem-se em direções diversas, não abrigando senão o seu lado de fora, 0 ermo e o distante.

Eis que, então, voltamos ao fim último da poesia, da literatura. Pois se trata, para Rosa, da interminável perseguição da nascente das palavras, a tentativa sem termo de atingir seu sentido original: "Se tem de haver uma frase feita, eu preferia que me chamassem de reacionário da língua, pois quero voltar cada dia à origem da língua, lá onde a palavra ainda está nas entranhas da alma". (Lorenz, 1995: 49) Descer às entranhas da palavra, voltar à sua origem, flagrar o breve lampejo de seu pré-nascimento, como se o seu ser (sua verdade?) se escondesse neste instante quando ela ainda não é, quando ainda está para ser, imersa no silêncio.

Essa busca insistente por uma linguagem adâmica, quase elíptica - de "grau zero", no dizer de Roland Barthes -, "como se a Literatura, tendendo desde há um século a transmutar sua superfície numa forma sem hereditariedade, só encontrasse pureza na ausência de qualquer signo" (Barthes, 1974: 119), é sem dúvida a ambição e a ventura de Guimarães Rosa, e se Tutaméia nos parece o momento em que esse desejo é enunciado do modo mais contundente, pressionando o escritor a levá-1o a cabo, o próprio trajeto de Rosa, desde Magma, revela um impulso nessa direção.

Ainda que a monumentalidade de Grande sertão: veredas ofusque em demasia os passos dessa busca, não podemos negligenciar alguns fatos: seu início como poeta não é, certamente, um mero acidente de percurso, pois irá ferir-1he profundamente 


\section{EMTESE}

Belo Horizonte, v. 6, p. I-253, ago. 2003

a linguagem, que, embora sob a forma de prosa, mergulha mais e mais no trabalho do verso, tensionando cada frase a seu limite assintático; também a sua inegável inclinação pela narrativa mais curta (os contos ou as estórias, até as novelas), sendo que mesmo o Grande sertão: veredas foi originalmente concebido como um conto, depois alongado (Brasil, 1969: 60); e ainda a sua declaração: "Não, não sou romancista; sou um contista de contos críticos." (Lorenz, 1995: 35)

Daí talvez pudéssemos depreender o rastro do movimento que se insinua com a obra de Rosa: algo como uma involução da escrita, travessia do grande sertão e suas veredas ao minúsculo e infinito sertão e seus vazios, experiência do que só sabe "desviver para trás, dia por dia" (Rosa, 1997: 80), do que só pode recuar, "como quem não tem frente, como quem só tem costas" (Rosa, 1997: 69) - e ler Tutaméia não como uma chegada ou um fim, mas, antes, como um ponto extremo, em que a literatura e a vida tendem ao dicionário, em que o ilimitado da linguagem dobra-se sobre o pequeno traço da letra, como um retorno impossivel, o instante em que as zonas fronteiriças se apagam: "Divulgo: que as coisas começam deveras é por detrás, do que há, recurso; quando no remate acontecem, estão já desaparecidas." (Rosa, 1967: 13.) Voltemos, então, ao momento de antes das palavras: aí quando a mão de um escritor segura o seu lápis. E o larga.

\section{A MÃO QUE ESCREVE, A MÃO QUE NÃO ESCREVE}

À primeira vista, a mão, esse pedaço do corpo que vai do punho aos dedos, parece dotada de grande mobilidade e refinamento sensitivo, uma vez que ela se destina, sobretudo, à preensão e ao exercício do tato. Ter algo em suas mãos é ter sobre isso posse e domínio, é ser capaz de exercer sobre tal objeto ou pessoa toda a sua destreza e habilidade. Que seria dos homens sem o poder das mãos para 0 trabalho, a guerra, o amor? Entretanto, nem sempre tudo está muito perto, à mão, em condições de ser facilmente tocado ou obtido. Nem sempre a mão tem autoridade 
suficiente mesmo sobre aquilo que ela pode abranger, que se acomoda confortavelmente em sua palma.

A mão de um escritor, a mão de alguém que escreve, que empunha o lápis, a pena, a caneta, fazendo-a vibrar, avançando com sua ponta qual uma arma, a lâmina de um estilete, essa mão, ela está só, destacada, não obedece senão ao próprio gesto a que foi entregue - escrever. Por mais que se esforce, um escritor jamais será senhor de sua caneta, dessa mão que desliza sob um ritmo e um tempo ainda inconcebíveis. Ao se penetrar nos domínios da literatura, todo domínio faz-se inviável: antes mesmo que se esboce, está já fadado ao fracasso. Dessa natureza inapreensível das palavras é que nos fala Blanchot; e é também ele quem nos alerta sobre a existência de uma outra mão e de sua força:

0 domínio do escritor não está na mão que escreve, essa mão "doente" que nunca solta o lápis, que não pode soltá-10, pois o que segura, não 0 segura realmente, o que segura pertence à sombra e ela própria é uma sombra. 0 dominio é sempre obra da outra mão, daquela que não escreve, capaz de intervir no momento adequado, de apoderar-se do lápis e de o afastar. Portanto, o domínio consiste no poder de parar de escrever, de interromper 0 que se escreve (...). (Blanchot, 1987: 15-6)

Parar de escrever, interromper a escrita dando um ponto de basta à sombra que com ela se move e se dilata - eis o verdadeiro poder de um escritor? Ése tanto mais escritor quanto não se escreve? Terá sido, então, o abandono da literatura por Rimbaud, Raduan Nassar, Luandino Vieira e outros o ato escritural por excelência de suas obras? Tais interrogações, por demais perigosas, acabam por colocar em causa a própria literatura; assim, como responder a elas? Se é com a literatura que essas questões se manifestam, certamente será apenas por meio dela que poderemos abordá-las. A experiência de Guimarães Rosa permite-nos um pensamento sobre a escrita que, margeando esses mesmos problemas, desloca-os para um outro lugar.

Com Tutaméia, o itinerário de Rosa atinge um ponto que, do interior da linguagem, pressiona as suas possibilidades e os seus limites, ou seja, o seu fora e a sua dissipação. Tomado pelo que poderíamos chamar de uma "lógica negativa", Tutaméia ergue-se sobre os pilares da ausência e daquilo que está prestes a desaparecer. Fazer-se pelo não, beirar sempre o próprio vazio: é essa, para Blanchot, a sina radical da arte - "a literatura vai para si própria, para sua essência, que 


\section{EMTESE}

Belo Horizonte, v. 6, p. I-253, ago. 2003

é o seu desaparecimento" (Blanchot, 1985: 205), o que nos devolve ao cerne das terceiras estórias: "0 livro pode valer pelo muito que nêle não deveu caber" (Rosa, 1967: 12), esclarece Rosa, logo de início, virando ao avesso a lógica da presença, como o monstruoso touro de "Hiato", que extrai seu existir do que ele não é:

Touro mor que nenhuns outros, e impossivel, nuca e tronco, chifres feito foices, o bôjo, arcabouço, desmesura de esqueleto, total desforma. (...) Remoto, o touro, de imaginação medonha - a quadratura da bêsta - ingenerado, prêto empedernido. Ordem de mistérios sem contôrno em mistérios sem conteúdo. 0 que 0 azul nem é do céu: é de além dêle. Tudo era possível e não acontecido. (Rosa, 1967: 61-2)

Assim, é sobre um hiato - um encontro de letras que mais marca a sua separação que a sua fusão -, é sobre um intervalo que se tece a língua remota e impossível dessas estórias, sustentada menos por sua mensagem, seu enredo, do que pelo corpo sutil das letras. Corpo que, como o touro - o outro? -, comporta em seu mínimo risco a total desforma da poesia, "havendo, demais, exorbitante", cicatriz do excesso e da desmesura: "Era enorme e nada". (Rosa, 1967: 62) A letra - mistério sem contorno nem conteúdo, aberta ao infinito, instante pontual em que a palavra já se ausenta e ainda está por se dizer - captura, para Rosa, o "sentido original" das palavras, concentra em si toda a potencialidade poética, ao mesmo tempo que a dissipa, fecha, faz desaparecer: é apenas isso, nada mais que isso, literalmente.

Construir uma língua que deposita a máxima possibilidade de sua poesia, o seu poder de indeterminação, no parco traço da letra, no mais determinado (diríamos até mesmo: limitado); tomar para si a "incumbência" de compor um livro que seja um "abreviado de tudo", valendo-se para tanto de estórias que mais parecem haikais, quase ideogramas, tal a economia de sua linguagem - como tais fatos poderiam nos fazer avançar em uma reflexão sobre a escrita e o silêncio? Como a mão que escreve, essa mão solitária, pode encontrar-se com a outra, aquela que prefere estancar o fluxo das palavras e parar? Talvez, ouvindo Rosa, possamos verdadeiramente começar por detrás e pensar que, para alguns escritores, - assim como, ao aprendermos a escrever, tornamo-nos destros ou canhotos - a mão que escreve é aquela que não escreve. Isso quer dizer que, paradoxalmente, o desejo de escrever pode, às vezes, recair sobre a mão que abre mão da escrita. Escrever parando de escrever: não há aî, entretanto, nenhum domínio, nenhuma destreza, mas, antes, uma paixão atormentada, desastrada, pelo que, nas palavras, é ausência e abandono. 
Essa paixão evidencia-se, em Tutaméia, desde o seu título, que é, segundo a definição do próprio autor, "nonada, baga, ninha", ao mesmo tempo que "mea omnia" (Rosa, 1967: 166), todas as minhas coisas. Assim, à medida que avançamos na leitura do livro, vamos nos deparando com uma outra língua, uma outra escrita, em que as palavras, comprimidas até o ponto de letra, de traço, de ponto, estão sempre realizando o trânsito improvável do tudo ao nada. Trânsito esse que Rosa procura configurar principalmente no primeiro prefácio - "Aletria e hermenêutica" -, dandonos a ver o que talvez pudéssemos chamar de uma poética da subtração: "por seqüência de operações subtrativas", ou através de "uma definição 'por extração'", o escritor colhe "imagens de eliminação parcial", "ou total", "ou seriada". (Rosa, 1967: 3-12) Completamente assolada por essa lógica subtrativa, pelo poder de negação criador que envolve a literatura, a escrita de Rosa perfaz-se, sobretudo, pela mão que não escreve: abraçando o risco de encontrar em sua gênese a própria morte, ela busca para si, como via real, o silêncio e o desaparecimento.

Portanto, se pensamos que escrever pode nos impedir de escrever, como disse Blanchot a respeito de Kafka, é necessário que indaguemos em que medida tal impossibilidade torna-se indissociável do próprio fazer literário, revertendo-se em sua condição e seu fundamento. E se tomamos Tutaméia como matéria privilegiada dessa reflexão, é porque aí o trabalho do escritor consiste em arremessar a língua ao seu satori, desfazendo-a num estado de iluminação e fulgurância (Rosa, 1967: 7-8) e permitindo-nos, assim, entrever a qual escrita pode nos conduzir a mão que não escreve:

Literatura inexaurivelmente eliptica, taciturna, criptica, obstinadamente retraída a qualquer literatura e, apesar disso, inacessivel aí mesmo onde parece se manifestar, exasperação de um ciúme que a paixão enleva para além de si mesma, acreditaríamos ter sido feita para o deserto ou para o exílio. Ela mantém o desejo na expectativa e, dizendo sempre muito ou muito pouco, ela o deixa a cada vez, sem deixá-10 jamais. (Derrida, 1995: 77) 


\section{EM TESE}

Belo Horizonte, v. 6, p. I-253, ago. 2003

RESUMÉ:

"Est-ce qu'il y aura quelque chose en commun entre l'expérience littéraire de Guimarães Rosa et les opérations de soustraction?" Cette question, née au cours de la lecture de Tutaméia, nous a mis devant un mouvement propre à l'écriture de Rosa - mouvement de condensation, $d^{\prime}$ abstraction et d'écartement - et nous a conduit vers l'élement constitutif du travail de l'ecrivain: pas tout simplement les mots, mais la lettre.

MOTS-CLÉS: Guimarães Rosa, soustraction, lettre.

\section{REFERÊNCIAS BIBLIOGRÁFICAS}

BARTHES, Roland. O grau zero da escritura. Trad. Anne Arnichand e Álvaro Lorencini. São Paulo: Cultrix, 1974. BLANCHOT, Maurice. O espaço literário. Trad. Álvaro Cabral. Rio de Janeiro: Rocco, 1987.

- O livro por vir. Trad. Maria Regina Louro. Lisboà: Relógio d'Água, 1984.

BRASIL, Assis. A chave da obra. In: Guimarães Rosa: ensaio. Rio de Janeiro: Organização Simões, 1969. p.55106.

DERRIDA, Jacques. Salvo o nome. Trad. Nícia Adan Bonatti. Campinas: Papirus, 1995.

LORENZ, Günter. Diálogo com Guimarães Rosa. In: ROSA, João Guimarães. Ficção completa. Rio de Janeiro: Nova Aguilar, 1995. v. 1. p. 27-61.

RÓNAI, Paulo. Os prefácios de Tutaméia. In: ROSA, João Guimarães. Tutaméia: terceiras estórias. 6. ed. Rio de Janeiro: Nova Fronteira, 1985. p. 215-20.

ROSA, João Guimarães. Magma. Rio de Janeiro: Nova Fronteira, 1997.

- Tutaméia: terceiras estórias. Rio de Janeiro: José 01 ympio, 1967. 